\title{
The vertical nitrogen flux caused by zooplankton diel vertical migration
}

\author{
Graeme C. Hays ${ }^{1, *}$, Roger P. Harris ${ }^{2}$, Robert N. Head ${ }^{2}$ \\ 'School of Biological Sciences, University of Wales Swansea, Singleton Park, Swansea SA2 8PP, United Kingdom \\ ${ }^{2}$ Plymouth Marine Laboratory, Prospect Place, Plymouth PL1 3DH, United Kingdom
}

\begin{abstract}
Three species of vertically migrating copepods (Pleuromamma pisekii, $P$. gracilis and $P$ abdominalis) were collected at dawn and at dusk from the upper $200 \mathrm{~m}$ in the North Atlantic $\left(36.5^{\circ} \mathrm{N}\right.$, $19.2^{\circ} \mathrm{W}$ ) between 11 and 18 July 1996. For all 3 species, the nitrogen content of individuals caught at dawn was significantly greater than for individuals caught at dusk. Theoretical considerations suggest that this dawn-dusk difference in nitrogen content represents material that is exported from the surface each day (the so called active $\mathrm{N}$-flux). The rate of this active $\mathrm{N}$-flux was $0.46 \mu \mathrm{g} \mathrm{N}$ ind. ${ }^{-1} \mathrm{~d}^{i}$ for $P$. pisekii, $0.34 \mu \mathrm{g} \mathrm{N}$ ind..$^{-1} \mathrm{~d}^{-1}$ for $P$. gracilis and $5.17 \mu \mathrm{g} \mathrm{N}$ ind.$^{-1} \mathrm{~d}^{-1}$ for $P$. abdominalis.
\end{abstract}

KEY WORDS: Zooplankton - Diel vertical migration Nitrogen Vertical export B Biogeochemical impact N-flux - Atlantic PRIME

\section{INTRODUCTION}

One of the major challenges of current oceanographic research is to develop mathematical models that describe the flow of material through oceanic ecosystems. Frequently such models are structured in terms of nitrogen, which in various forms, such as nitrate, nitrite and ammonia, is a key nutrient for phytoplankton growth (Falkowski 1997). In order to construct realistic ecosystem models it is important to quantify the rate at which nitrogen is lost from the surface mixed layer of the ocean (e.g. Fasham et al. 1993). It has traditionally been thought that this loss of nitrogen occurs mainiy through the passive sinking of detrital material (e.g. Smith et al. 1986), with the rate of this loss being quantified by deploying floating sediment traps beneath the thermocline. Recently, however, it has been argued that a second major avenue for nitrogen loss from the surface layer may be through the normal diel vertical migration (NDVM) of omnivorous zooplankton, with this avenue being termed the active N-flux (Longhurst \& Harrison 1988).

\footnotetext{
•E-mail: g.hays@swan.ac.uk
}

NDVM behaviour occurs in a wide variety of taxa with the general pattern being for migrant species to feed near the surface at night and then to fast at greater depths during the day. In the North Atlantic, for example, Longhurst \& Williams (1979) reported that NDVM was particularly marked in euphausiids and copepods of the genera Euchaeta, Pleuromamma and Metridia. There are 2 distinct ways in which NDVM may lead to an active $\mathrm{N}$-flux. First, material ingested near the surface at night may be defecated at depth during the day (Angel 1984). Second, material ingested near the surface and then assimilated may be excreted, for example as ammonia, at depth (Longhurst \& Harrison 1988). These 2 processes will liberate particulate organic nitrogen (PON) and dissolved nitrogen (DN) at depth respectively.

For an active PON-flux to occur, the residence time of material in the gut must be sufficiently long so that zooplankton still contain fecal material when they arrive below the thermocline (Angel 1984). Even small migrating copepods may swim vertically at high speed le.g. Metridia may swim at up to $90 \mathrm{~m} \mathrm{~h}^{-1}$ (Enright 1977)] and hence where there is a shallow seasonal thermocline migrants will probably descend to below the thermocline in a matter of minutes. Furthermore, 
recent evidence suggests that gut evacuation rates may be particularly slow for vertical migrants (Morales et al. 1993, Atkinson et a.l. 1996). For example, Morales et al. (1993) showed that for Pleuromamma and Metridia in the NE Atlantic, it would take approximately $1 \mathrm{~h}$ for $50 \%$ of the gut contents to be defecated. Hence it is likely that after the cessation of feeding and the dawn descent, a large proportion of the gut contents of migrants will be defecated below the thermocline.

Excretion by migrating zooplankton will continue during the day because excretory products are continuously produced as a result of basic metabolism. In general, excretory products in zooplankton have a high nitrogen content as a result of the deamination of amino acids and peptides assimilated from the food (Raymont 1983). The rate of the active DN-flux has been estimated indirectly by using measurements of the rate of ammonium $\left(\mathrm{NH}_{4}^{+}\right)$excretion derived from laboratory incubations. In this way it has been estimated that the active DN-flux may be relatively high, approaching or even exceeding that caused by the passive sinking of particulate material (Longhurst \& Harrison 1988, Dam et al. 1995). Furthermore, these are likely to be conservative estimates of the true rate of the active DN-flux since in addition to $\mathrm{NH}_{4}{ }^{+}$, nitrogen may also be excreted in other forms such as urea and/or amino acids (Webb \& Johannes 1967, Mayzaud \& Dallot 1973)

While the active N-flux is therefore likely to be an important process which has implications for the overall ecosystem dynamics, current estimates for the rate of this flux are tentative. As a step towards resolving the true rate of the active $\mathrm{N}$-flux, we have recently suggested that the measurement of diel changes in the nitrogen content of migrating zooplankton may provide a technique for its in situ assessment (Hays et al. 1997). In this paper we report the first attempt to apply this new approach in the field.

\section{MATERIALS AND METHODS}

Theoretical basis for measuring the active $\mathbf{N}$-flux. Since migrating zooplankton feed predominantly above the thermocline at night but may continue to excrete and defecate below the thermocline during the day when they are fasting, a diel change in their nitrogen content is predicted. Nitrogen content is predicted to reach a minimum just prior to the onset of feeding around dusk, increase during the night as zooplankton feed near the surface, and reach a maximum at the end of the night just prior to the dawn descent. Hence the difference between the nitrogen content of zooplankton at dawn and at dusk will represent the daily export of nitrogen per individual.
Field sampling. Sampling was conducted in the NE Atlantic between 11 and 18 July 1996 at $36.5^{\circ} \mathrm{N}\left( \pm 0.4^{\circ}\right)$ and $19.2^{\circ} \mathrm{W}\left( \pm 0.05^{\circ}\right)$ and was concentrated around dusk and dawn when the minima and maxima in the nitrogen content of migrating zooplankton were predicted. Zooplankton were collected using a $500 \mu \mathrm{m}$ WP-2 net hauled vertically between $200 \mathrm{~m}$ and the surface. The times of sunset and sunrise at the study site were 20:30 and 06:15 h respectively. 'Dusk' samples were collected between 20:00 and 21:30 h and 'dawn' samples between 04:30 and 05:50 h with the net generally being deployed once at dusk and once at dawn on each day. Upon retrieval of the net, zooplankton were immediately anaesthetized by gently pouring the contents of the cod end into a 1:5 soda-water/seawater solution.

The most abundant diel vertical migrants were found to be 3 copepod species of the genus Pleuromamma: P. pisekii, $P$. gracilis and $P$. abdominalis. As soon as the net was retrieved, the catch was sorted under a binocular microscope and adult females of these 3 species were picked out, placed into tin capsules (Elemental Microanalysis Limited) and frozen at $-20^{\circ} \mathrm{C}$. All sorting was completed within approximately 30 min of the net being retrieved. For $P$. pisekii between 5 and 20 individuals were placed in each tin capsule, for $P$. gracilis there were between 6 and 17 individuals per capsule, while for $P$. abdominalis there were between 1 and 5 individuals per capsule. These numbers of copepods per capsule ensured that there was enough material for the subsequent elemental analysis. In August 1996, after return of the samples to the laboratory, they were dried at $50^{\circ} \mathrm{C}$ for $2 \mathrm{~d}$ and then analyzed on a Carlo Erba NA1500 elemental analyzer.

Temperature profiles were made several times a day using a Neil Brown Mark III CTD. All times are given as Greenwich Mean Time (GMT).

\section{RESULTS}

In all the CTD profiles the same general pattern was evident with temperatures of about $20.5^{\circ} \mathrm{C}$ at the surface, a thermocline at 30 to $40 \mathrm{~m}$ and temperatures of 13 to $15^{\circ} \mathrm{C}$ below the thermocline down to $300 \mathrm{~m}$ (Fig. 1).

The number of zooplankton samples that we collected is summarised in Table 1 . At dusk, the mean nitrogen content per individual was $6.01 \mu \mathrm{g} N$ for Pleuromamma pisekii $(\mathrm{SE}=0.18 \mu \mathrm{g} \mathrm{N}), 4.94 \mu \mathrm{g} \mathrm{N}$ for $P$. gracilis ( $\mathrm{SE}=0.14$ ), and $25.25 \mu \mathrm{g} \mathrm{N}$ for $P$. abdominalis ( $\mathrm{SE}=1.78$ ) with the nitrogen content appearing to be independent of the exact time in the evening that the sample was collected (Fig. 2). The mean nitrogen content per individual at dawn was $6.47 \mu \mathrm{g} \mathrm{N}$ for $P$. pisekii 
Table 1. For dawn and dusk net deployments on each sampling day, the number of samples that were run through the elemental analyser for each species and the total number of individuals that were contained within these samples. All individuals were adult females

\begin{tabular}{|c|c|c|c|c|c|c|c|c|c|c|c|c|c|c|c|c|c|}
\hline \multirow[t]{2}{*}{ Day in July: } & \multicolumn{2}{|c|}{11} & \multicolumn{2}{|c|}{12} & \multicolumn{2}{|c|}{13} & \multicolumn{2}{|c|}{14} & \multicolumn{2}{|c|}{15} & \multicolumn{2}{|c|}{16} & \multicolumn{2}{|c|}{17} & \multicolumn{2}{|c|}{18} & \multirow[t]{2}{*}{ Total } \\
\hline & Dawn & Dusk. & Dawn & Dusk & Dawn & Dusk & Dawn & Dusk & Dawn & Dusk & Dawn & Dusk & Dawn & Dusk & Dawn & Dusk & \\
\hline \multicolumn{18}{|c|}{ Pleuromamma pisekii } \\
\hline No. samples & 1 & 3 & 4 & 0 & 5 & 2 & 0 & 0 & 4 & 1 & 0 & 1 & 2 & 1 & 1 & 0 & 25 \\
\hline No. individuals & 9 & 29 & 60 & 0 & 75 & 30 & 0 & 0 & 64 & 14 & 0 & 10 & 20 & 8 & 5 & 0 & 324 \\
\hline \multicolumn{18}{|l|}{ P. gracilis } \\
\hline No. samples & 2 & 3 & 3 & 0 & 3 & 3 & 0 & 2 & 4 & 2 & 0 & 1 & 1 & 2 & 1 & 0 & 27 \\
\hline No. individuals & 25 & 45 & 45 & 0 & 45 & 45 & 0 & 30 & 52 & 30 & 0 & 17 & 12 & 27 & 6 & 0 & 379 \\
\hline \multicolumn{18}{|l|}{ P. abdominalis } \\
\hline No. samples & 0 & 4 & 6 & 0 & 9 & 4 & 0 & 0 & 7 & 1 & 0 & 0 & 1 & 0 & 1 & 0 & 33 \\
\hline No. individuals & 0 & 17 & 30 & 0 & 43 & 20 & 0 & 0 & 31 & 3 & 0 & 0 & 5 & 0 & 4 & 0 & 153 \\
\hline
\end{tabular}

$(\mathrm{SE}=0.14), 5.28 \mu \mathrm{g} \mathrm{N}$ for $P$. gracilis $(\mathrm{SE}=0.15)$ and $30.42 \mu \mathrm{g} \mathrm{N}$ for $P$. abdominalis (SE = 1.06) (Fig. 3).

The mean nitrogen content of individuals sampled at dawn was significantly higher than for individuals sampled at dusk for all 3 species: for Pleuromamma pisekii, 1 -tailed $t$-test, $t_{15}=2.03, \mathrm{p}=0.03$; for $P$. gracilis, 1 -tailed $t$-test, $t_{24}=1.67, \mathrm{p}=0.05 ;$ for $P$. abdominalis, 1 tailed $t$-test, $t_{14}=2.5, p=0.01$. The difference between the mean dawn and dusk nitrogen values was $0.46 \mu \mathrm{g}$ $\mathrm{N}$ ind. ${ }^{-1}$ for $P$. pisekii, $0.34 \mu \mathrm{g} \mathrm{N}$ ind ${ }^{-1}$ for $P$. gracilis and $5.17 \mu \mathrm{g} \mathrm{N}$ ind.$^{-1}$ for $P$. abdominalis. When expressed as a percentage of the mean dawn nitrogen content, the difference between the mean dawn and dusk values was $7.0 \%$ for P. pisekii, $6.5 \%$ for P. gracilis and $17.0 \%$ for $P$. abdominalis (Fig. 4).

\section{DISCUSSION}

While the biogeochemical impacts of normal diel vertical migration (NDVM) have only recently begun

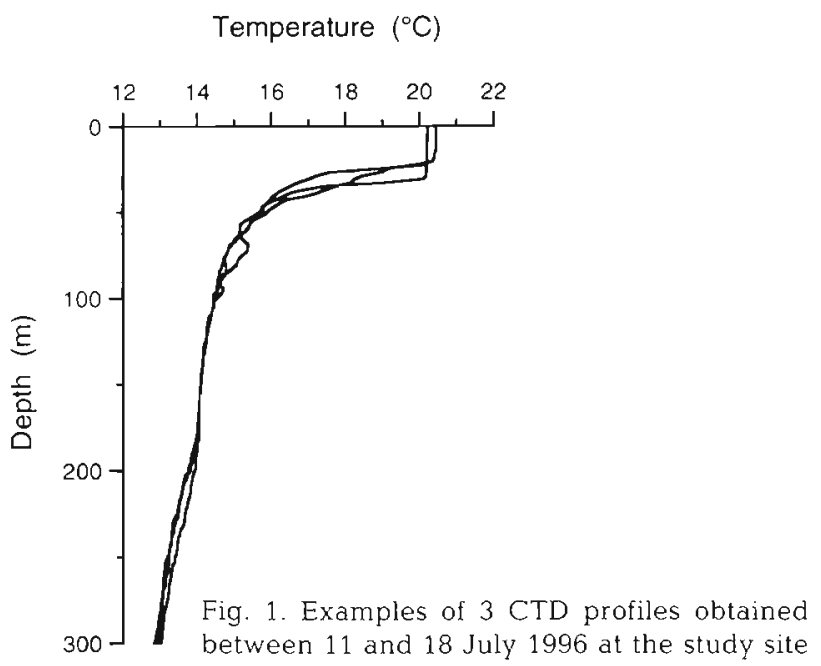

to be considered, the extent and timing of NDVM in different species has been very well documented. Although there may be some spatio-temporal and
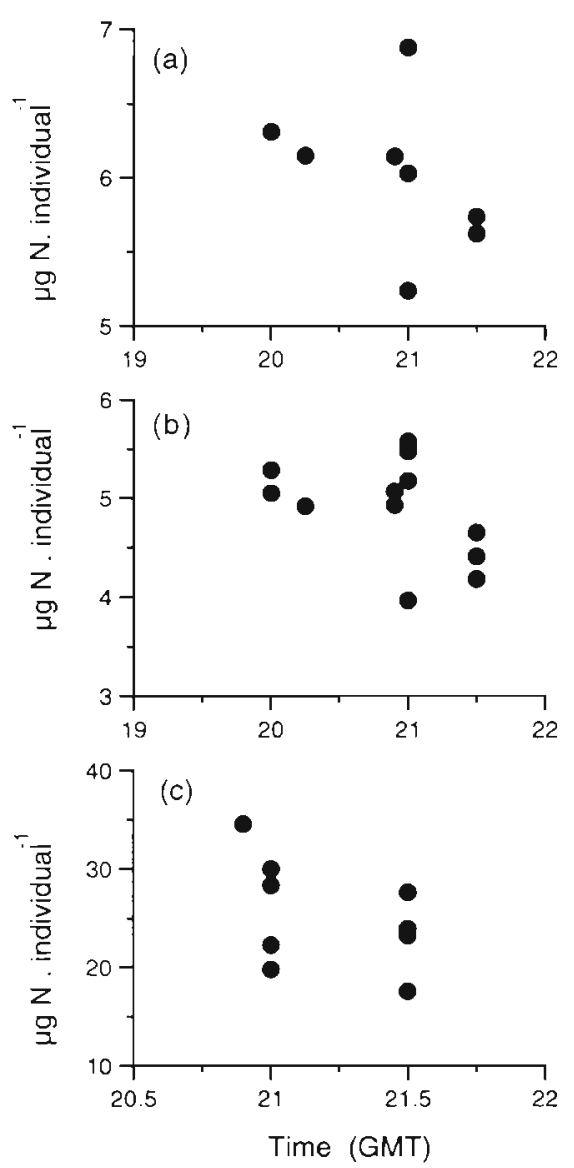

Fig. 2. Body nitrogen content of (a) Pleuromamma pisekii, (b) P. gracilis and (c) P. abdominalis individuals collected at different times close to dusk. Each point represents a mean value for several individuals (see text for details). For none of the species did the nitrogen content change significantly within this time scale. $F_{1,6}=1.2, \mathrm{p}=0.32 ; F_{1,11}=2.0, \mathrm{p}=0.18$; and $F_{1,7}=1.7, \mathrm{p}=0.23$ respectively 

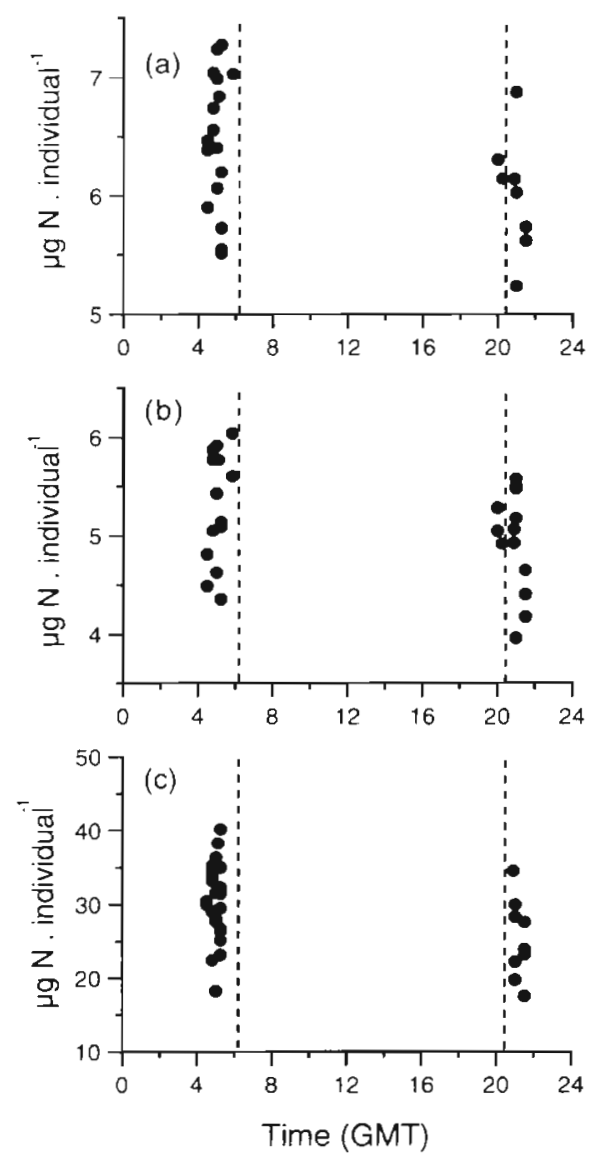

Fig. 3. Body nitrogen content of (a) Pleuromamma pisekii, (b) $P$. gracilis and (c) $P$. abdominalis individuals sampled at different times of the day. Each point represents a mean value for several individuals (see text for details). Times of sunrise and sunset are indicated by dashed lines

inter-specific differences, the timing of NDVM generally follows a pattern of a dawn descent and a dusk ascent. It is well known that copepods of the genus Pleuromamma are, along with other members of the family Metriididae, strong diel vertical migrants. For example, Longhurst \& Williams (1979) reported for the NE Atlantic that the depth of maximum abundance for $P$. robusta was between 400 and $500 \mathrm{~m}$ during the day while this species tended to be near the surface at night, and that Metridia lucens was most abundant between 300 and $400 \mathrm{~m}$ during the day and, again, at night was maximally abundant near the surface. Similarly, Buskey et al. (1989) reported that during the day in the Sargasso Sea, P. gracilis was maximally abundant between 200 and $400 \mathrm{~m}$. We have recently hypothesised that for vertical migrants there will be a difference in the nitrogen content between dusk and dawn which represents the daily export from near the surface (Hays et al. 1997). In the current study our objective was to test this hypothesis by characterising
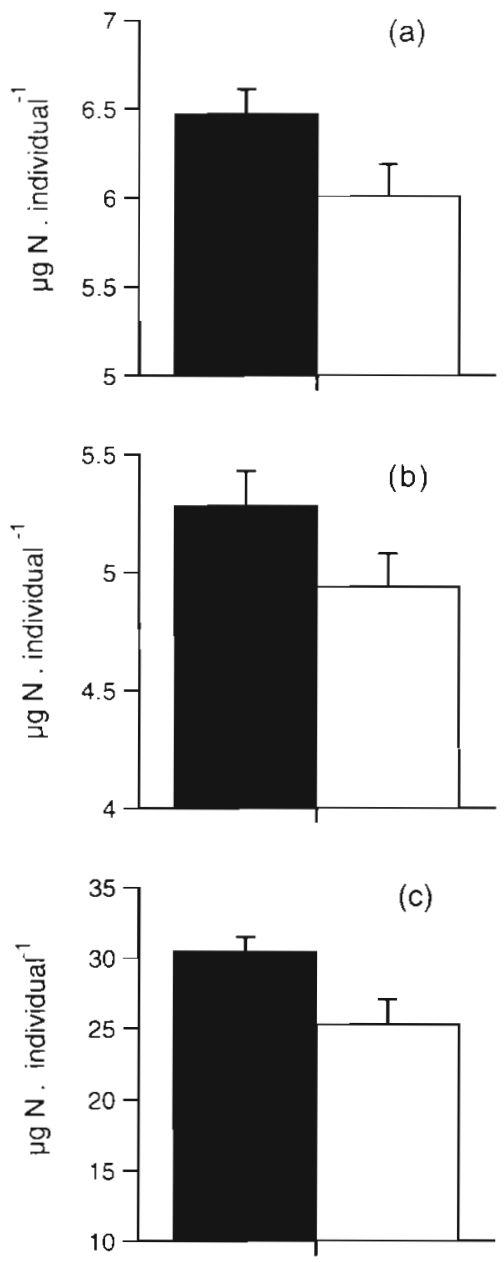

Fig. 4. Mean body nitrogen content (+1 SE) for individuals collected at dawn (ם) and at dusk ( $\square$ ) for (a) Pleuromamma pisekii, (b) P. gracilis and (c) P. abdominalis

the mean dawn and dusk nitrogen contents for a variety of species. For the 3 species examined there was indeed a significant reduction in the body nitrogen content between dawn and dusk which represented between 6.5 and $17 \%$ of the migrating biomass.

We can use literature values to infer the relative contributions of excretion and defecation to this reduction in the nitrogen content. In this context the most extensive and appropriate excretion rates are provided by Longhurst et al. (1989) for zooplankton from the North Atlantic $\left(38^{\circ} \mathrm{N}, 65^{\circ} \mathrm{W}\right)$. They measured excretion rates for migrating zooplankton caught below the thermocline during the day, which they maintained at subthermocline temperatures and deprived of food, i.e. in conditions which matched as closely as possible those that migrating zooplankton would naturally experience during the day. Furthermore their samples were dominated by Pleuromamma species and the temperature below the thermocline was $17^{\circ} \mathrm{C}$, i.e. similar to 
that in our study. The mean excretion rate reported was $0.062 \mu \mathrm{g}$-at. $\mathrm{N} \mathrm{mg}^{-1}$ dry wt $\mathrm{h}^{-1}$. Assuming nitrogen equaled $9.3 \%$ of the dry weight (Longhurst \& Harrison 1988 ), this excretion rate equals $0.93 \%$ of the body nitrogen $\mathrm{h}^{-1}$. If we assume that the zooplankton in our study were beneath the thermocline between dawn and dusk (approximately $14 \mathrm{~h} \mathrm{~d}^{-1}$ ), the calculated excretion below the thermocline is $13 \%$ of the body nitrogen. This is comparable to the values we have cal culated from the diel changes in nitrogen content (6.5, 7.0 and $17.0 \%)$. In contrast, Carlotti \& Hirche (1997) constructed an individual-based bioenergetic model for the copepod Calanus finmarchicus (broadly similar in size to the copepods examined in our study) and estimated that after feeding the amount of carbon in the gut reached about $1 \%$ of the total carbon content of an individual. Most of this material in the gut will be assimilated and hence the amount of material defecated from a single full gut will be very small $(\ll 1 \%)$ compared to the total amount in the body.

The implication of these calculations is that the active $\mathrm{N}$-flux is probably mediated largely through nitrogenous excretion (i.e. the active DN-flux) rather than through defecation (i.e the active PON-flux). Furthermore the rate of the active N-flux will not be strongly influenced by whether defecation occurs above the thermocline prior to descent or below the thermocline after descent, since the vast majority of the vertical export must be occurring via the excretion of dissolved nitrogen. In terms of our sampling strategy (integrated net hauls between $200 \mathrm{~m}$ and the surface), it is, consequently, probably unimportant whether the zooplankton collected at dawn were actually above the thermocline with fuller guts or below the thermocline with emptier guts.

Our dusk sampling series might be criticised on the basis that our integrated net hauls could have included zooplankton that had already arrived at the surface and begun to feed. If this were the case, then the nitrogen content would be greater for the zooplankton we collected later on in the evening and consequently we would be underestimating the true rate of the active $\mathrm{N}$ flux. However, in none of the species was there any evidence for an increase in nitrogen content as the evening progressed, which suggests that our dusk samples were composed of zooplankton that had not yet begun to feed.

The rate of the active $\mathrm{N}$-flux may potentially vary due to a number of factors such as inter-specific differences in excretion rates and/or regional and seasonal differences in water temperature. Furthermore, the rate of the active $\mathrm{N}$-flux will be influenced by the length of time spent below the thermocline each day. It is well known that larger species of diel vertical migrants tend to spend longer beneath the thermocline each day (e.g. Hays 1995). This is presumably because larger species tend to be more visible to visual predators and hence, in order to maximize their survival, they need to arrive near the surface when it is darker. If they have the same excretion rates, larger species will, therefore, excrete more nitrogen below the thermocline each day due to their longer sub-thermocline residence. Our observation that the rate of the active $N$-flux was highest in the largest of the species considered (Pleuromamma abdominalis) is consistent with this suggestion.

In conclusion, our measurements lend further support to the suggestion that vertically migrating zooplankton may actively export nitrogen from the ocean surface and open the way for further quantification of the rate of this export which will ultimately allow this flux to be incorporated into ecosystem models.

Acknowledgements. We thank all the officers and crew of the RRS 'Discovery' for their invaluable help during the sampling program and Polly Machin (BODC) for supplying the CTD data. This paper forms part of PRIME (Plankton Reactivity in the Marine Environment), a programme funded by the Natural Environment Research Council of the UK. This is PRIME contribution number 62

\section{LITERATURE CITED}

Angel MV (1984) Detrital organic fluxes through pelagic ecosystems. In: Fasham MJR (ed) Flows of energy and materials in marine ecosystems. Theory and practice. Plenum Press, New York, p 475-516

Atkinson A, Ward P, Murphy EJ (1996) Diel periodicity of subantarctic copepods: relationships between vertical migration, gut fullness and gut evacuation rate. J Plankton Res $18: 1387-1405$

Buskey EJ, Baker KS, Smith RC, Swift E (1989) Photosensitivity of the oceanic copepods Pleuromamma gracilis and Pleuromamma xiphias and its relationship to light penetration and daytime depth distribution. Mar Ecol Prog Ser $55: 207-216$

Carlotti F, Hirche HJ (1997) Growth and egg production of female Calanus finmarchicus: an individual-based physiological model and experimental validation. Mar Ecol Prog Ser 149:91-104

Dam HG, Roman MR, Youngbluth MJ (1995) Downward export of respiratory carbon and dissolved inorganic nitrogen by diel-migrant mesozooplankton at the JGOFS Bermuda time-series station. Deep Sea Res I 42:1187-1197

Enright JT (1977) Copepods in a hurry: sustained high-speed upward migration. Limnol Oceanogr 22:118-125

Falkowski PG (1997) Evolution of the nitrogen cycle and its influence on the biological sequestration of $\mathrm{CO}_{2}$ in the ocean. Nature 387:272-275

Fasham MJR, Sarmiento JL, Slater RD, Ducklow HW Williams R (1993) Ecosystem behavior at Bermuda Station 'S' and Ocean Weather Station 'India': a general circulation model and observational analysis. Global Biogeochem Cycles 7:379-415

Hays GC (1995) Ontogenetic and seasonal variation in the diel vertical migration of the copepods Metridia lucens and Metridia longa. Limnol Oceanogr 40:1461-1465 
Hays GC. Harms RP, Head RN, Kennedy H (1997) A technique for the in situ assessment of the vertical nutrogen flux caused by the diel vertical migration of zooplankton. Deep Sea Res I 44:1085-1089

Longhurst AR, Bedo A, Harrison WG, Head EJH, Horne EP, Irwin B, Morales C (1989) NFLUX: a test of vertical nitrogen flux by diel migrant biota. Deep Sea Res 1 36:1705-1719

Longhurst AR, Harrison WG (1988) Vertical nitrogen flux from the oceanic photic zone by diel migrant zooplankton and nekton. Deep Sea Res I 35:881-889

Longhurst A. Williams R (1979) Materials for modeling: vertical distribution of Atlantic zooplankton in summer. J Plankton Res 1:1-28

Mayzaud P, Dallot S (1973) Respiration et excrétion azotée du zooplancton. I. Evaluation des niveaux métaboliques de

Editorial responsibility: Otto Kinne (Editor),

Oldendorf/Luhe, Germany quelques espèces de Méditerranée occidentale. Mar Biol 19:307-314

Morales CE. Harris RP, Head RN, Tranter PRG (1993) Copepod grazing in the oceanic northeast Atlantic during a 6 week drifting station: the contribution of size classes and vertical migrants. J Plankton Res 15:185-211

Raymont JEG (1983) Plankton and productivity in the oceans Vol 2, Zooplankton, 2nd edn. Pergamon Press, Oxford

Smith SV, Kimmerer WJ, Walsh TW (1986) Vertical flux and biogeochemical turnover regulate nutrient limitation of net organic production in the North Pacific gyre. Limnol Oceanogr 31:161-167

Webb KL, Johannes RE (1967) Studies of the release of dissolved free amino acids by marine zooplankton. Limnol Oceanogr 12:376-382

Submitted: July 9, 1997: Accepted: October 24, 1997 Proofs recelved from author(s): November 28, 1997 